term beds might be needed per head of population. It merely observed that the most important groups would be elderly people with chronic organic brain syndromes, elderly patients with chronic schizophrenia who had already spent most of their lives in hospital, new schizophrenics who failed to respond to energetic treatment, some people with chronic affective disorders, and a few brain damaged alcoholics.

The working party's most interesting suggestions, however, concerned the type of hospital such patients are likely to need. It was emphatic that neither existing mental illness hospitals nor units in district general hospitals alone would provide an adequate basis for inpatient care. Instead, it suggested creating a "mental health campus," which might, if situated sufficiently centrally, develop on the site of an existing mental hospital. The campus would contain a range of distinct facilities, including separate assessment and short term care units for geriatric and younger patients, separate medium term to long term units for the elderly developing dementia and for young patients, a special unit for brain damaged patients with intractable behavioural problems, and day hospitals. The main campus would be surrounded by smaller satellite units on other sites and would act as "a nucleus around which community care in its various guises can be planned and deployed." The frequent and regular movement of staff of all disciplines between the campus and its satellites would be "an essential element."

The most important issue remains unresolved, however: now many beds will be needed in the future and for whom?
No one doubts that the improved community facilities the government's long delayed acceptance of the Griffiths recommendations should eventually create should give scope for further reductions in hospital populations, particularly in Scotland, which still had 319 inpatients per 100000 population in $1985 .{ }^{6}$ At the same time it seems likely that the cost of treating the most severely disabled patients in the community will exceed that of traditional residential care if unacceptable burdens are not to be placed on families and friends. ${ }^{10}$ If the health departments are seriously interested in health services research here is a problem crying out for attention.

Professor of Psychiatry,

University of Edinburgh Department of Psychiatry,

Royal Edinburgh Hospital,

Edinburgh EH10 5HF

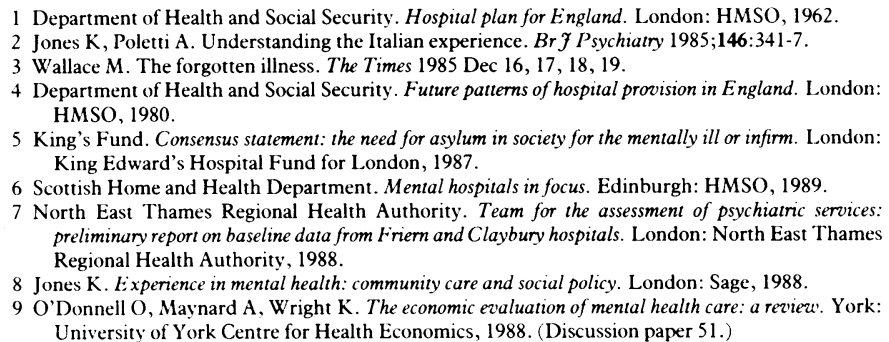
HMSO, 1980.

5 King's Fund. Consensus statement: the need for asylum in society for the mentally ill or infirm. London: King Edward's Hospital Fund for London, 1987.

6 Scottish Home and Health Department. Mental hospitals in focus. Edinburgh: HMSO, 1989.

7 North East Thames Regional Health Authority. Team for the assessment of psychiatric services: preliminary report on baseline data from Friern and Claybury hospitals. London: North East Thames Regional Health Authority, 1988.

8 Jones K. Experience in mental health: community cure and social policy. London: Sage, 1988.

9 O'Donnell O, Maynard A, Wright K. The economic evaluation of mental health care: a review. York: University of York Centre for Health Economics, 1988. (Discussion paper 51.)

10 Häfner H. Do we still need beds for psychiatric patients? Acta Psychiatr Scand 1987;75:113-26.

\title{
Experiments on animals
}

\section{Scientists should be looking for alternatives}

The recently released Statistics of Scientific Procedures on Living Animals for Great Britain 1988 makes uncomfortable reading for those who take seriously the interests of nonhuman sentient creatures. ' It shows that about 3.5 million scientific procedures on animals were started in Britain during 1988. Though that total continues a downward trend over the years, the reduction since 1987 has been a mere $4 \%$.

The more detailed breakdowns give particular grounds for concern. Despite strong-and surely well justifiedopposition to the use of animals for testing products such as cosmetics and toiletries, the number of these procedures jumped more than $15 \%$ to 17000 . The numbers of other toxicology and safety tests also increased to the point at which 588000 animals were used. At least 232000 of these tests appear to have been carried on to the point of death for some or all of the animals. Given that most of the other animals will at least have been made extremely ill, the quantity of suffering here is vast. It seems highly doubtful that all of this testing was for essential new substances of great benefit to humans: much product development is commercially directed and designed to produce "me too" products that will make inroads into the sales of competitors.

Procedures entailing the application of substances to the eye numbered 78000 , and all but 3000 were without the use of anaesthesia (though we do not know how many of the remainder caused pain). In 24000 procedures psychological stress was induced.

These statistics have appeared as the result of the second year of operation of the Animals (Scientific Procedures) Act 1986. This was intended to ensure that animal experimentation would go ahead only when it was considered clear that the work was important enough to outweigh the cost to the animals. Yet, as the animal welfare movement predicted, the statistics show that the act has allowed animal experimentation to continue largely as before without any drastic rethinking.

The ethical case for a more far reaching change has been presented often enough, but it is as often distorted by its opponents. It does not depend on any kind of sentimental love for animals, nor on any fanatical or "absolutist" morality which holds that it is never justifiable to take the life of an animal for any purpose. The real basis of the case against animal experimentation is that animal pain and suffering should not be given less weight than similar amounts of pain and suffering occurring in humans. Such comparisons will necessarily be rough, but that is not to deny that there are clear cases in which we know how the balance goes and can say with confidence that we would not allow similar experiments on humans incapable of consenting. In these circumstances it is pure speciesism - an unjustifiable bias towards our own species - to allow the experiments on animals. Discrimination on the basis of species alone is no more justifiable than discrimination on the basis of race alone. In both cases we favour members of our own group, not because of any relevant characteristic that makes them suffer less, but simply because they belong to our group.

The application of truly non-discriminatory standards to animal experimentation would mean the end of the institutional practice of animal experimentation as we know it. If this is considered too radical a change to introduce all at once, we should still not find it beyond our ingenuity to cut the amount of animal experimentation by $40 \%$, rather than $4 \%$, 
annually. Only a few months ago the international cosmetics firms Avon and Revlon announced that they had found ways to ensure the safety of their products without animal experimentation. This was a response to years of pressure from the animal liberation group. It will save thousands of animals every year from painful, often lethal, tests. ${ }^{2}$

Opposition to animal experimentation shows every sign of being with us for many years to come, since its philosophical foundation is clear and difficult to gainsay. Among scientists in the United States, where standards of regulation for animal experimentation lag far behind even those in Britain, there are signs of a reflex defensiveness which can lead only to polarisation and increasing hostility between experimenters and the animal liberation movement. ${ }^{3}$ Doctors and scientists in Britain should resist this tendency to overrespond. Instead they should look for ways in which they can make a radical break with a past in which animal experimentation has been accepted with far too little questioning.

Director,

PETER SINGER

Centre for Human Bioethics,

Monash University, Melbourne,

Victoria 3168, Australia

1 Home Office. Statistics of scientific procedures on living animals. London, HMSO, 1988. (Cmnd 743)

2 Gill L. Beauty and the beasts. The Times $1989 \mathrm{Jul} \mathrm{5,} \mathrm{p15,} \mathrm{cols} \mathrm{7-8.}$

3 Council on Scientific Affairs. Animals in research. FAMA 1989;261:3602-6.

\section{Treatment of persistent pain}

\section{Behavioural methods give good results}

Patients with persistent benign pain present a problem for all clinicians from whom they seek help. The biomedical model of illness encourages doctors to believe that where there is pain there is a pathological lesion and that if we probe enough we will find it. ${ }^{1}$ Treating the disorder will then cure the pain. The problem with patients with persistent pain is that either we cannot find a lesion to treat or we have no treatment for a known lesion. Do behavioural approaches have anything to offer these unfortunate patients?

The behaviourist would suggest that this model of illness is inappropriate in chronic pain, which is best viewed as a complex of dysfunctions-neurophysiological, emotional, and social - with associated changes in behaviour. ${ }^{23}$ Patients show features such as depression, sleeplessness, inactivity, unfitness, excessive consumption of drugs, pain behaviour, and cognitive dysfunction, which though secondary to the pain form a symptom complex similar wherever its site. This pattern has been labelled the chronic pain syndrome. ${ }^{4}$

Fordyce was the first to treat such patients in a behavioural setting. He argued that many of these dysfunctions could be seen as learned maladaptive behaviours and could be changed, as can any behaviour, if the contingencies of the behaviour are altered. ${ }^{5} \mathrm{He}$ showed that by using "operant conditioning" patients' pain behaviour could indeed be abolished and their functions improved. ${ }^{67}$ Subsequent work has developed this approach, adding cognitive elements, and today most American pain clinics offer behavioural techniques. Treatment may vary from a few outpatient sessions to a stay of several weeks in an inpatient unit. The programmes are usually run by psychologists and staffed by a multidisciplinary team including physiotherapists, nurses, and occupational therapists.

Are such programmes the solution of our patients with chronic pain? The first point that has to be made is that such approaches do not "cure" the pain, nor do they attempt to, and thus to use this as a yardstick of their success is inappropriate. They do aim to restore patients to normal function in spite of the pain, and the gains in this area can be remarkable and extremely gratifying for both the patient and therapist. Published reports have come mostly from the United States for patients with low back pain; these suggest that $60-70 \%$ of patients will make changes..$^{8-11}$ In particular, patients increase their activity, ${ }^{12-1+}$ have fewer pain behaviours, ${ }^{15}$ require fewer drugs, ${ }^{71617}$ are able to return to work, ${ }^{18}$ and make less future use of health care facilities. ${ }^{19} 20$ Depressive symptoms may be strikingly improved, ${ }^{21}$ and the intensity of the pain may be reduced. ${ }^{12}{ }^{1719}$ Long term follow up suggests that the changes are maintained. ${ }^{12} 1+22$

Though some of the early data were poor, ${ }^{9}$ more recent studies have been better designed and controlled and have longer follow up..$^{23}$ Many questions have still to be answered, however; the type of patient and pain most suited, the components of the treatment responsible for the changes, and whether inpatient programmes are superior to outpatient programmes. Inpatient programmes in the United States may cost up to $\$ 25000$ per patient, but they are usually funded by workers' compensation schemes on the basis that the treatment is effective and economically sound.

Doctors in Britain could be forgiven for knowing little about such approaches because there are few programmes in this country and few outcome data. ${ }^{2+}$ This does not reflect lack of suitable patients, of whom there are an alarming number, but rather ignorance of the approach and lack of the resource. Interest is increasing, however, with various pain clinics starting outpatient groups and reporting results ${ }^{25}$ and the grant funded inpatient unit at St Thomas's receiving an ever increasing number of referrals.

Patients with chronic pain suffer greatly and are avid and often inappropriate users of health care resources. Behavioural treatment can make economic and humanitarian sense.

C E PITHER

Medical Director INPUT,

St Thomas's Pain Management Centre,

St Thomas's Hospital,

London SE1 7EH

\footnotetext{
1 Engel GL. The need for a new medical model: a challenge for biomedicine. Science 1977;196: 129-36.

2 Turk DC, Meichenbaum D, Genest M. Pain and behavioural medicine: a cognitive behavioural perspective. New York: Guildford, 1983.

Sanders SH. A trimodal conceptualisation of clinical pain. Percept Mot Skills 1979:48:551-5.

4 Pinsky JJ. Chronic intractable benign pain: a syndrome and its treatment with intensive short-term group psychotherapy. I Human Stress 1978;4:17-21.

group psychotherapy. I Human Stress 1978;4:17-21.
Fordyce WE. Behavioural methods for chronic pain and illness. St Louis: Mosby, 1976.

6 Fordyce WE. Behavioural methods for chronic pain and illness. St Louis: Mosby, 1976. ordyce WE, Fowler R, Lehman J, DeLateu
chronic pain. f Chronic Dis 1968;21:179-90.

7 Fordyce WE, Fowler R, Lehman J, DeLateur B, Sand P, Treischman R. Operant conditioning in the treatment of chronic pain. Arch Phys Med Rehabil 1973;54:399-408.

Turner JA, Chapman CR. Psychological interventions for chronic pain: a critical review. Pain 1982;13:23-46.

Linton SJ. A critical review of behavioural treatments for chronic benign pain other than headache. Br f Clin Psychol 1982;21:321-37.

10 Aronoff GM, Evans WO, Enders PL. A review of follow up studies of multidisciplinary pain units. Pain 1983;16:1-11.

11 Keefe FT, Gil KM, Rose SC. Behavioural approaches in the multidisciplinary management of chronic pain: programmes and issues. Clin Psych Rev 1986;6:87-113.

2 Chapman SL, Brena SF, Bradford LA. Treatment outcome in a chronic pain rehabilitation program. Pain 1981;11:255-68.

program. Pain 1981;11:255-68.
3 Swanson D, Swenson W, Maruta T, McPhee M. Program for managing chronic pain. Mavo Clin Proc 1976:51:401-11.
} 